M. B. Золхоева. Гуманизм как основополагающий принцип социального взаимодействия в контексте обсуждения проблемы жизни и смерти

УДК $1: 316$

DOI: 10.18101/1994-0866-2019-4-43-49

\title{
ГУМАНИЗМ КАК ОСНОВОПОЛАГАЮЩИЙ ПРИНЦИП СОЦИАЛЬНОГО ВЗАИМОДЕЙСТВИЯ В КОНТЕКСТЕ ОБСУЖДЕНИЯ ПРОБЛЕМЫ ЖИЗНИ И СМЕРТИ
}

\author{
(C) Золхоева Мария Валентиновна \\ доктор философских наук, доцент, \\ заведующая кафедрой философии, \\ Бурятский государственный университет имени Доржи Банзарова \\ Россия, 670000, г. Улан-Удэ, ул. Смолина, 24a \\ E-mail: badmaeva_maria@mail.ru
}

В статье рассматривается значение гуманизма в процессах социальных взаимодействий, особенно в разрезе отношения общества к неизлечимым пациентам, нуждающимся в паллиативной медицинской помощи. Для развития и совершенствования института паллиативной помощи, созданного по инициативе Всемирной организации здравоохранения (ВО3) в конце XX в., необходимо существенное изменение общественного сознания, господствующей системы ценностей с позиций подлинного гуманизма, неэгоистического альтруизма, о роли которого в жизни социума писал выдающийся русско-американский социолог, философ Питирим Сорокин. Подобное изменение предусматривает переосмысление извечной философской проблемы жизни и смерти на основе целостного, холистического толкования феномена бытия, согласно которому смерть не выступает отрицанием, противоположностью жизни, а является закономерным процессом, не исключающим принципов гуманизма, альтруизма и утверждения жизни. Аргументируя данную позицию, автор обращается к идеям и теориям, сложившимся в различных культурных и философских системах прошлого.

Ключевые слова: жизнь; смерть; гуманизм; альтруизм; паллиативная медицинская помощь; Всемирная организация здравоохранения; древнекитайская философия; древнеегипетская «Книга мертвых»; Артур Шопенгауэр; Питирим Сорокин.

\section{Для цитирования}

Золхоева М. В. Гуманизм как основополагающий принцип социального взаимодействия в контексте обсуждения проблемы жизни и смерти // Вестник Бурятского государственного университета. Философия. 2019. Вып. 4. С. 43-49.

Проблема жизни и смерти - одна из основных проблем философии. Издавна человек, будучи разумным существом, способным осознавать конечность собственного бытия, задумывается о том, что ждет его после жизни, за чертой единственного известного ему существования. Отсутствие опыта жизни после смерти уже в древности обусловило страх и благоговение перед смертью как неизвестным и абсолютно неизбежным завершением пути любого человека. Потому тема смерти, поиск рецептов бессмертия присутствуют практически в каждой культурной системе и соотносятся с представлениями о ценности и смысле жизни. Единства в различных мировоззренческих системах в обсуждении этих вопросов нет. Однако чаще всего люди пытаются, опираясь на собственный разум, найти воз- 
можность «примириться» с неотвратимостью смерти и наполнить смыслом бессмысленное на первый взгляд, в силу своей конечности, существование человека в мире живых.

Древнекитайская философия, например, не противопоставляла телесное и духовное начала, рассматривая их в качестве не просто взаимосвязанных, но взаимоположенных сущностей, составляющих единое бытие-становление, непрерывный поток изменений и трансформаций. Не случайно поэтому, что важнейшая в рассматриваемой традиции категория ци трактуется как некая субстанция, проявляющаяся и в форме духа, и в форме вещества. Подобным образом абсолютное противопоставление между жизнью и смертью в древнекитайском сознании отсутствует. На это, в частности, указывает и П. С. Гуревич: «В древнекитайском сознании... факт смерти оценивался как нечто, не имеющее глубокого бытийственного значения. Иначе говоря, если человек умер, никакой трагедии в этом нет. Он все равно остается среди живых, но уже как усопший. Здесь так же, как и там. Мертвый уходит от живых условно, в каком-то ограниченном смысле. Он нас не покидает. Мир плотно заселен «живыми мертвецами». Они перешли в другое состояние, но не ушли в иной мир. Вот почему в этой культуре символика смерти носила земной характер. За богдыханом (императором Китая) повсюду следовал гроб, который считался атрибутом его земного существования. Заблаговременная подготовка могилы для престарелых родителей считалось актом заботы и милосердия. Покинув часть земного мира, усопший отправлялся к другим людям, которые умерли раньше, но все же никуда не исчезли. Отсюда культ предков, который весьма характерен для этой культуры» [3, с. 185].

Не разделяли бытие и небытие, жизнь и смерть и в Древнем Египте. Согласно древнеегипетской «Книге мертвых», смерть, в обычном понимании трактуемая как завершение, окончание жизненного пути, как противоположность жизни, вообще не существует. «Никто и ничто не умирает. Все меняется, все трансформируется. Рождение и смерть - две стороны единой жизни. Смерть - это не конец, а лишь новое начало. Это возрождение, продолжение существования Бессмертной Души человека в мире ином, продолжение ее странствия через Вечность» [5].

Выдающийся философ XIX в. А. Шопенгауэр идет дальше и подчеркивает особую значимость не жизни, а смерти для каждого человека. Сама человеческая жизнь трактуется им как пребывание в «неподлинном бытии» представлений, цепь сменяющих друг друга невзгод и страданий. Смерть же, напротив, способна избавить человека от страданий повседневной жизни, и потому Шопенгауэр считает ее настоящей целью существования каждого человека, дающей понимание того, что лучше бы полностью освободиться от ее оков, сделав выбор в пользу истинного бытия, бытия мира Воли. Смерть, по мнению философа, убивает в человеке изначально присущий ему эгоизм, вынуждающий его на протяжении всей жизни считать себя единственным центром мироздания. Она отрезвляет человека и позволяет прийти к истинному пониманию вещей [8, с. 222-298].

Рассмотренные выше точки зрения сформировались задолго до XXI в., до разрушительных мировых войн, уже ставшего привычным ожидания апокалипсиса вследствие непрекращающегося уничтожения человеком окружающей среды, фатального нарастания межгосударственных противоречий, угрозы ядерного столкновения, глобального старения населения Земли, повсеместного роста хронических прогрессирующих заболеваний и т. п. 
M. B. Золхоева. Гуманизм как основополагающий принцип социального взаимодействия в контексте обсуждения проблемы жизни и смерти

Статистика только онкологических заболеваний в современном мире свидетельствует о том, что «ежегодно в мире выявляется более 10 млн новых случаев злокачественных новообразований, таким образом, ежедневно примерно 27 тыс. пациентам ставят этот диагноз. На сегодняшний момент в мире от рака страдает более 14 млн человек, из которых 8200000 погибает... По прогнозам ВОЗ (Всемирной организации здравоохранения), за 20 лет показатели смертности и заболеваемости от рака увеличатся в 2 раза: число новых случаев заболевания вырастет с 10 млн до 20 млн, а летальность с 6 млн до 12 млн» 1 .

В Европе увеличивается количество стран, законодательно допускающих добровольный уход из жизни при наличии соответствующих медицинских показаний. Сегодня эвтаназия официально разрешена в Голландии, Люксембурге, Бельгии, Швеции и Швейцарии. Россия в этот список стран, легитимизировавших добровольный уход из жизни, не входит, эвтаназия в России запрещена. Ее альтернативой в нашем государстве является паллиативная медицинская помощь инкурабельным (неизлечимым) больным, предполагающая применение разнообразных процедур, нацеленных на облегчение состояния больного. Термин «паллиативный» происходит от латинского «раllium» («маска», «плащ»). Это означает, что паллиативная помощь призвана скрывать проявления тяжелейшего недуга, защищать, «укрывать плащом» тех, кто нуждается в помощи и поддержке. Впервые о паллиативной помощи как социальном институте, располагающем академическими и клиническими организациями, осуществляющими необходимые научные исследования, заговорили в 70-х гг. XX в., когда Всемирная организация здравоохранения выступила за развитие паллиативной помощи в целом ряде государств западного мира, среди которых были Швейцария, США, Великобритания, Канада, Голландия, Бельгия, Франция и Австралия. В 1980-х гг. по инициативе ВОЗ адекватное обезболивание и возможность назначения опиоидов для больных раком стали реальностью и в других частях света.

Феномен паллиативной помощи и все вопросы, связанные с ее организацией и оказанием, потребовали комплексного изучения. Поэтому в 1982 г. эксперты объявили о необходимости создания нового направления здравоохранения и предложили определение понятия «паллиативная помощь», согласно которому последняя представляет собой помощь тем больным, радикальное лечение которым уже не показано. Эта трактовка предполагала активную и всестороннюю помощь пациентам в тех случаях, когда их лечение признавалось неэффективным, т. е. на последних стадиях заболевания. Получателями паллиативной помощи были названы пациенты со злокачественными новообразованиями. При этом главной задачей врача становилось купирование боли и других патологических симптомов, а также решение социальных, психологических и духовных проблем больного. Целью оказания паллиативной помощи стало достижение наилучшего качества жизни больных и их семей.

Однако уже в начале XXI в., в 2002 году, в связи с увеличением числа больных хроническими прогрессирующими заболеваниями ВОЗ уточнила первона-

1 Российский онкологический портал [Электронный ресурc]. URL: https://www. oncoforum.ru/o-rake/statistika-raka/zabolevaemost-i-smertnost-ot-raka-v-mire.html (дата обращения: 11.11.2019). 
чальное определение паллиативной помощи, указав на необходимость предоставления таковой пациентам с любыми инкурабельными хроническими заболеваниями, представляющими угрозу для жизни пациента, а также на то, что принципы паллиативной помощи должны быть применены на самых ранних стадиях лечения больных, что позволяет успешнее бороться с симптомами заболеваний и добиваться в борьбе с недугом максимально возможных результатов.

Кроме того, согласно этому определению объектами паллиативной медицинской помощи стали не только сами пациенты, но и близкие им люди, переживающие тяжелую утрату и нуждающиеся в поддержке со стороны квалифицированного медицинского персонала после смерти пациента ${ }^{1}$.

Таким образом, паллиативная помощь - это не просто уход за тяжело и неизличимо больным пациентом. Это особое отношение общества к человеку, осознающему свой неуклонно приближающийся и неизбежный уход из жизни, выстроенное тем не менее на принципах гуманизма, утверждения жизни и понимании смерти как нормального и абсолютно закономерного процесса. Она не ставит целью продление срока жизни больного, не дает бессмысленных обещаний, но обеспечивает необходимую поддержку, максимально возможный уровень качества жизни пациента, его активное и конструктивное взаимодействие с другими людьми на весь период времени, которым он располагает.

Именно гуманизм, альтруистическое, доброжелательное, лишенное эгоизма отношение к ближнему является, на наш взгляд, основополагающим принципом оказания паллиативной помощи и немаловажным фактором развития человека и общества в целом.

Гуманное, альтруистическое поведение как важнейший фактор успешности в жизни любого сообщества отмечает и отечественный психолог, антрополог, философ А. П. Назаретян. В своей книге «Нелинейное будущее. Мегаистория, синергетика, культурная антропология и психология в глобальном прогнозировании» ученый задается вопросом о том, почему представители разных видов рода Ното не смогли мирно сосуществовать друг с другом на протяжении длительного времени. Ответ он находит в исследованиях Ю. И. Семенова, предположившего существование грегарно-индивидуальной формы отбора, обеспечившей преимущество в межвидовой конкуреции тем популяциям, которые отличались более высоким уровнем развития взаимодействий внутри группы. Это, по мнению А. П. Назаретяна, способствовало сохранению более слабых, но менее агрессивных и обладающих более тонкой нервной организацией особей, которые были способны к нестандартному поведению и занимались чрезвычайно важной для жизни племени деятельностью: изготовлением орудий, поддержанием огня, лечением соплеменников, накоплением и трансляцией жизненно важных знаний и умений. В результате «...лучшие перспективы развития... имели те стада, где все взрослые получали доступ к охотничьей добыче и к половым контактам, где была лучше организована взаимопомощь, слабые от рождения или вследствие ранений могли выжить, обогащая генофонд, накапливая и передавая коллективный опыт. Сообще-

\footnotetext{
${ }^{1}$ Паллиативная помощь и уход при ВИЧ/СПИД. 2006 [Электронный ресурс]. URL: https://medic.studio/meditsina-palliativnaya/palliativnaya-pomosch-uhod-pri-vich.html (дата обращения: 11.11.2019).
} 
M. В. Золхоева. Гуманизм как основополагающий принцип социального взаимодействия в контексте обсуждения проблемы жизни и смерти

ства со сниженным уровнем внутренней агрессивности оказывались жизнеспособнее при обострившейся конкуренции и, в частности, готовыми более эффективно организовать сражение, систему боевой координации и коммуникации. Так в процессе грегарного отбора продолжалось становление общеисторической зависимости между силой, мудростью и жизнеспособностью в проточеловеческих социумах» $[4$, с. 141$]$.

Осмыслению роли и значения в жизни социума подлинного альтруизма, неэгоистической творческой любви особое внимание уделил и выдающийся русскоамериканский философ, социолог П. Сорокин.

Сорокин говорит о любви-агапэ - символе самоотверженности, щедрости, самоотдачи, любви, изливающейся на добрых и злых, больных и здоровых, бедных и богатых. Образцами такой любви считаются Будда, Иисус Христос, Махатма Ганди. В противоположность этому любовь-эрос эгоистична, своевольна, не отказывается от своих стремлений и желаний.

Питирим Сорокин размышляет о восстанавливающей и исцеляющей силе любви: «... враждебная, раздраженная и недружелюбная эмоция лишает человека душевного спокойствия и в связи с этим (и другими путями) подрывает его здоровье и жизнеспособность. И наоборот, эмоции любви, симпатии и дружбы способствуют созиданию душевного покоя, самообладания в отношениях с окружающими и миром вообще: по этой и иным причинам такие эмоции оказывают живительный и целительный эффекты на организм при тех или иных нарушениях его деятельности» [6, с. 265].

Энергия любви обладает огромной силой, способствует сплочению народов и социальных групп, достижению единства и согласия. Сорокин чрезвычайно высоко оценивает роль творческой неэгоистической любви как средства урегулирования существующих между людьми конфликтов и сохранения человеческого общества. Ни одна человеческая группа, считает ученый, не в состоянии не только развиваться, но и выжить без минимума жизненной энергии любви, без минимума альтруизма в поведении ее членов. Если не заботиться о младенцах, они умрут, и их смерть положит конец существованию группы. Эта забота не всегда приятна и во многих случаях она не приносит никакой выгоды. Абсолютно эгоистичные люди, лишенные любви или симпатии, предпочтут быть свободными от столь обременительных обязанностей. Но если такая свобода практикуется всеми или большинством, группа прекратит свое существование. Увеличение бездетных браков в наше время уже закончилось в большинстве западных обществ неизменной численностью населения, а во многих случаях - уменьшением численности. Вдохновленная эгоизмом, практика освобождения от обременительного ухода за детьми и заботы о детях уже ставит западный мир на грань самоубийства.

Без минимума альтруизма все больные, нетрудоспособные и старые члены группы также скоро умрут. Для законченного эгоиста нет резона заниматься столь неприятной деятельностью, как уход за стариками и немощными. Только любовь, симпатия и сострадание могут мотивировать их. Следовательно, общество, состоящее только из законченных эгоистов, не выживет.

Эгоисты не могут создать творческого общества, живущего в мире. Лишенные взаимной симпатии и чувства долга, они будут заняты непрерывной борьбой. Расцветут подозрение, разрушительность и внутренние интриги: война всех со всеми станет правилом. Мирное, гармоничное и творческое общество может существовать, только 
если его члены обладают хотя бы минимумом любви, симпатии и жалости, обеспечивающими взаимопомощь, сотрудничество и хороший уход. В этих условиях его члены объединяются в одно коллективное «мы», в котором радости и печали каждого разделяются всеми остальными. В такой группе каждый член не изолированный атом, а важная часть творческого сообщества. В такой атмосфере обязанности выполняются с радостью, бремя забот переносится легче, жизнь наполнена смыслом, превалирует безмятежный мирный разум.

Если будут превалировать силы любви, силы позитивной, гуманистической поляризации, то «с человечеством все будет в порядке», заключает Сорокин. Если силы деморализации и дезинтеграции победят, то будущее человечества окажется мрачным и неопределенным. Чем больше созидательной энергии любви накапливается в системе культуры, тем более мощным является ее культурный слой, тем более она устойчива, стабильна и независима от внешних воздействий.

Действительное достижение высоких показателей гуманизма, на наш взгляд, требует глобальных изменений в общественном сознании, в практике взаимотношений общества и государства, в работе всех без исключения социальных институтов, предполагающих сознательное воспитание подлинно гуманного отношения, прежде всего, к наименее защищенным, нуждающимся в посторонней помощи субъектам социального взаимодействия, к которым в нашем случае относится все множество инкурабельных больных. В связи с этим необходимым представляется формирование в обществе нового отношения к проблемам жизни и смерти, понимание того, что ценность человеческой жизни не определяется ее длительностью, что борьба за максимально высокое качество жизни для любого человека, даже не имеющего ни единого шанса на полное выздоровление и восстановление всей полноты функциональных возможностей, является действительной целью жизни общества, каждого человека. В этом убеждении, в этой деятельности человек обретает свою сущность, свое подлинно человеческое бытие, воплощающее подлинные общечеловеческие ценности, находящиеся вне времени и пространства, вне бесчисленных социальных и физиологических различий. Тем самым человек, общество в целом обретают настоящий смысл, настоящую цель своей жизни, будущее, предполагающее бесконечную перспективу развития и совершенствования.

\section{Литература}

1. Введенская Е. С. О важности принятия рабочего определения паллиативной помощи и ее содержания в преддверии становления служб в регионах // Проблемы стандартизации в здравоохранении. 2013. № 1-2. С. 24-29.

2. Введенская Е. С. О формировании современного понимания паллиативной помощи // Проблемы социальной гигиены, здравоохранения и истории медицины. 2013. № 3. C. $29-32$.

3. Гуревич П. С. Философская антропология: учеб. пособие. М.: Вестник, 1997. 448 с.

4. Назаретян А. П. Нелинейное будущее. Мегаистория, синергетика, культурная антропология и психология в глобальном прогнозировании. М.: АРГАМАК-МЕДИА, 2017. $512 \mathrm{c}$.

5. Сикирич Е. Вечная мудрость Древнего Египта // Новый Акрополь. 2001. № 4 [Электронный pecypc]. URL: https://www.newacropolis.ru/magazines/ 4_2001/Vechn_ mudr_dr_Egipta/ (дата обращения: 11.11.2019).

6. Сорокин П. А. Главные тенденции нашего времени. М.: Наука, 1997. 351 с. 
7. Ходаревская Ю. А. Философские основы жизни и смерти инкурабельного онкологического больного, утратившего надежду на выздоровление в паллиативной помощи // Наука и современность. 2011. № 8-2 [Электронный ресурc]. URL: http://cyberleninka.ru/ article/n/filosofskie-osnovy-zhizni-i-smerti-inkurabelnogo-onkologicheskogo-bolnogoutrativshego-nadezhdu-na-vyzdorovlenie-v-palliativnoy\#ixzz42xwzcCyg (дата обращения: 11.11.2019).

8. Шопенгауэр А. Мир как воля и представление. М., 1993. 669 с.

9. Sorokin P. A. The Reconstruction Of Humanity. Boston: Beacon Press, 1948. 247 p.

10. Sorokin P. A. The Ways and Power of Love. Types, Factors, and Techniques of moral Transformation. Boston: Beacon Press, 1954. 552 p.

\title{
HUMANISM AS A FUNDAMENTAL PRINCIPLE OF SOCIAL INTERACTION IN THE CONTEXT OF DISCUSSING A LIFE AND DEATH PROBLEM
}

\author{
Mariya V. Zolkhoeva \\ Dr. Sci. (Philos.), A/Prof., Head of Philosophy Department, \\ Dorzhi Banzarov Buryat State University \\ 24a Smolina St., Ulan-Ude 670000, Russia \\ E-mail: badmaeva_maria@mail.ru
}

The article discusses the importance of humanism in the processes of social interaction, especially in relation to incurable patients who need palliative care. For the development and improvement of the palliative care institution created on the initiative of the World Health Organization (WHO) at the end of the $20^{\text {th }}$ century the public consciousness and value system should undergo substantial transformation from a perspective of true humanism and unselfish altruism, about the role of the latter in society the outstanding RussianAmerican sociologist and philosopher Pitirim Sorokin wrote. Such a change involves the rethinking of the eternal philosophical problem of life and death on the basis of a holistic interpretation of the phenomenon of being, according to which death is not a negation, a polarity to life, but a natural process that does not exclude the principles of humanism, altruism and life approval. Arguing this position, we turn to the ideas and theories that have developed in various cultural and philosophical systems of the past.

Keywords: life; death; humanism; altruism; palliative care; World Health Organization (WHO); ancient Chinese philosophy; Ancient Egyptian "Book of the Dead"; Arthur Schopenhauer; Pitirim Sorokin. 